Check for updates

Cite this: RSC Adv., 2017, 7, 26392

Received 13th April 2017

Accepted 12th May 2017

DOI: $10.1039 / c 7 r a 04204 c$

rsc.li/rsc-advances

\section{Effects of electrochemical reaction and surface morphology on electroactive surface area of porous copper manufactured by Lost Carbonate Sintering $\dagger$}

\begin{abstract}
Pengcheng Zhu (D) and Yuyuan Zhao
Porous metals are potentially excellent electrode materials because of their high specific surface areas. The electroactive surface area is dependent on the electrochemical reaction and can be affected by the surface morphology. This work measured the electroactive surface area of porous Cu manufactured by the Lost Carbonate Sintering process, using the cyclic voltammetry (CV) peak current method and employing two reactions with different Nernst diffusion layer thicknesses. The real surface area was also measured by the double layer capacitance method. The effects of $\mathrm{Cu}$ particles size, sintering temperature and chemical treatment on the surface morphology and therefore surface areas were investigated. $\mathrm{Cu}$ particle size had a modest effect, with the medium particle sizes, 20-45 $\mu \mathrm{m}$ or 45-75 $\mu \mathrm{m}$, showing the highest surface areas. Increasing the sintering temperature from $850{ }^{\circ} \mathrm{C}$ to $950{ }^{\circ} \mathrm{C}$ or etching the samples by $5 \mathrm{M}$ nitric acid for 5 minutes reduced the electroactive and real surface areas by $31-61 \%$ or $9-25 \%$, respectively. The electroactive surface area was increased by up to 2 times when the diffusion layer thickness was decreased from $50 \mu \mathrm{m}$ to $1 \mu \mathrm{m}$.
\end{abstract}

\section{Introduction}

Open-cell porous metals are potentially excellent electrode materials in energy generation and storage due to their unique combinations of material and structural characteristics. ${ }^{1}$ Their applications include lithium-ion battery, ${ }^{2,3}$ alkaline zinc battery, ${ }^{4}$ nickel-hydrogen battery, ${ }^{5}$ solid oxide fuel cell ${ }^{6,7}$ and electrochemical capacitor. ${ }^{8}$ The performance of porous electrodes depends strongly on the magnitude of their specific surface area, because a higher specific surface area offers more reaction sites for reactants or a larger storage capacity for electrons per unit volume of electrodes, generating a higher energy density. Characterisation of surface area is therefore essential, especially for porous electrodes. The surface area of a number of porous metals manufactured by different processes, including porous $\mathrm{Ni}^{9,10}$ and $\mathrm{Au}^{11}$ have been measured by BET. However, the active surface area of porous electrodes has been found to be sensitive to the electrochemical process involved. ${ }^{12}$

Diao et al. ${ }^{12}$ developed a cyclic voltammetry (CV) peak current method to measure the electroactive surface area of porous copper manufactured by a space holder process, based on the

School of Engineering, University of Liverpool, Liverpool L69 3GH, UK. E-mail: sgpzhu@liverpool.ac.uk; Tel: +44 07709606856

$\dagger$ Electronic supplementary information (ESI) available. See DOI: $10.1039 / \mathrm{c} 7 \mathrm{ra} 04204 \mathrm{c}$ principle that the anodic or cathodic peak current for a diffusion controlled reaction is proportional to the electroactive surface area of the electrode. ${ }^{13}$ They chose the predominant anodic current peak and used a series of polished copper plates with known surface areas to establish the quantitative relation between electroactive surface area and peak current for copper. Using this quantitative relation, the electroactive surface area of a series of porous $\mathrm{Cu}$ samples with different pore sizes and porosities was determined from the measured peak current. In their work, however, the other current peaks in the cyclic voltammograms were not considered. Several questions then arise. Can other current peaks also be used for electroactive surface area measurements? If they can, would they measure a different electroactive surface area? What is the key factor causing the difference?

The electroactive surface area measured by the CV peak current method is expected to be reaction-dependent, because different reactions may be controlled by the diffusion of different reactant species. The Nernst diffusion layer determines the regime of the diffusion in a porous electrode and will have an influence on the electroactive surface area ref. 9. There are two diffusion regimes, depending on the thickness of the Nernst diffusion layer relative to the size of the interstices in the porous structure. ${ }^{14-17}$ If the diffusion layer is thinner than the size of the interstices, semi-infinite diffusion occurs. If the diffusion layer is comparable to or greater than the interstices, then thin layer diffusion occurs. A porous 
electrode is expected to contribute more to the detectable electroactive surface area with a thinner Nernst diffusion layer. Using different reactions in the $\mathrm{CV}$ peak current method will provide a powerful tool not only to measure surface areas at different length scales but also to study the effect of surface morphology on the surface area of porous metals.

It is well known that the surface area of porous metals is very sensitive to the surface morphology. ${ }^{18-20}$ Campell and Bakker ${ }^{21}$ electrodeposited a mesoporous nickel film onto a common porous nickel and founded that the surface area was increased by up to 35 times. Grden et al. ${ }^{18}$ compared INCO porous nickel before and after nitric acid etching and showed that the etching increased the electroactive surface area by about $150 \%$ because of increased surface roughness. Tan et al. ${ }^{19}$ reported that the surface area of a nanoporous gold was decreased by up to 3.5 times when it was annealed at $400{ }^{\circ} \mathrm{C}$, because the annealing flattened the surface. However, very little research, apart from ref. 10, has been carried out to date on the surface area of porous metals manufactured by powder metallurgy based methods and even less on how the surface area is affected by thermal and chemical treatments.

In this paper, we studied the surface areas of porous copper manufactured by the Lost Carbonate Sintering (LCS) process. ${ }^{22,23}$ The porous metal samples manufactured by the LCS process have representative porous structure produced by the powder metallurgy based space-holder methods, with highly-controllable porosity, pore size and pore shape. Two electrochemical reactions with different Nernst diffusion layer thicknesses were employed to measure the electroactive surface area using the CV peak current method. The real surface area was measured by the double layer capacitance method. The pore surface morphology of the LCS porous



Fig. 1 Schematic of the LCS process for manufacturing porous $\mathrm{Cu}$. copper was modified by using different copper particle sizes, sintering conditions and chemical etching, and their effects on the electroactive and real surface areas were investigated.

\section{Experimental}

\subsection{Preparation of porous copper samples}

Porous $\mathrm{Cu}$ samples with different pore sizes and porosities were manufactured by the LCS process, ${ }^{22}$ as shown schematically in Fig. 1. The raw materials were commercially pure $\mathrm{Cu}$ powder (Ecka Granules Metal Powder Ltd., Wednesdbury, UK) and food grade $\mathrm{K}_{2} \mathrm{CO}_{3}$ powder (E\&E Ltd., Melbourne, Australia). The $\mathrm{Cu}$ powder had spherical particles and was sieved into four different ranges of particle sizes: $<20 \mu \mathrm{m}, 20-45 \mu \mathrm{m}, 45-75$ and 75-90 $\mu \mathrm{m}$. The $\mathrm{K}_{2} \mathrm{CO}_{3}$ powder had rounded particles with a particle size range of $1000-1500 \mu \mathrm{m}$. The $\mathrm{Cu}$ and $\mathrm{K}_{2} \mathrm{CO}_{3}$ powders were mixed with an intended volume fraction of $\mathrm{Cu}$ according to the target porosity. The mixture was compacted at $200 \mathrm{MPa}$ by a hydraulic press. The obtained preform was then sintered in a vacuum furnace. Two different sintering
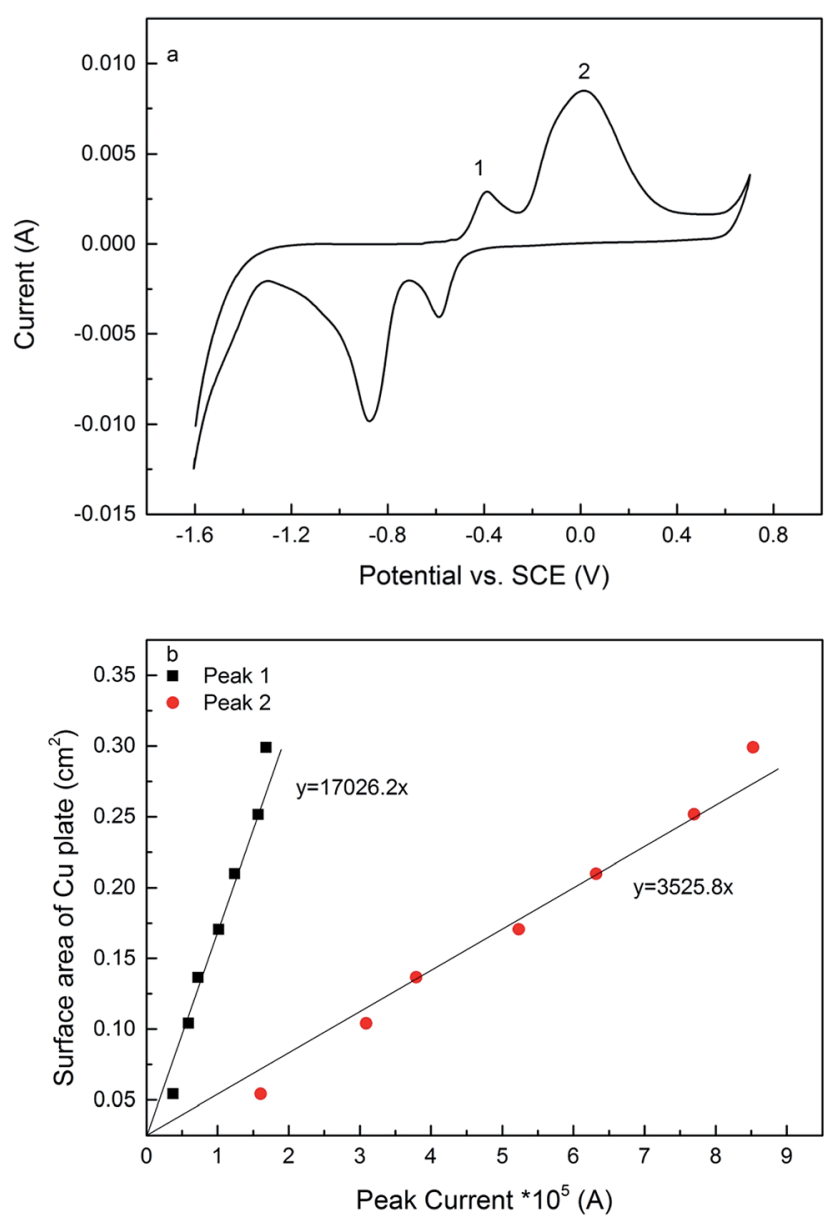

Fig. 2 (a) Typical current-potential plot of porous copper in $0.1 \mathrm{M}$ $\mathrm{KOH}$ in the potential range of -1.6 to $0.7 \mathrm{~V}$ at a scan rate of $0.01 \mathrm{~V} \mathrm{~s}^{-1}$. (b) Linear relations between peak current and surface area for mirror polished copper plates. 
temperatures were used to effect different surface morphologies. A group of the preforms were sintered at $850{ }^{\circ} \mathrm{C}$ for 4 hours and the $\mathrm{K}_{2} \mathrm{CO}_{3}$ particles were subsequently removed by dissolution in hot water. The other group of preforms were sintered at $950{ }^{\circ} \mathrm{C}$ for 2 hours and the $\mathrm{K}_{2} \mathrm{CO}_{3}$ particles were removed by decomposition during the sintering. The asproduced porous copper samples were cut to a uniform size of $5 \mathrm{~mm} \times 5 \mathrm{~mm} \times 4.8 \mathrm{~mm}$ by an electrical discharge machine (Prima E250, ONA Ltd., Bristol, UK), see ESI Fig. S1. $\dagger$ The morphology of the LCS porous $\mathrm{Cu}$ samples was observed by a scanning electron microscope (JSM-6610, Japan).

\subsection{Chemical etching}

The as-produced porous $\mathrm{Cu}$ samples were ultrasonically cleaned in dilute hydrochloric acid to remove the copper oxide on the surface and then washed with distilled water. The samples were subsequently chemically etched and the electroactive and real surface areas were measured both before and after etching. The etching treatment was carried out by immersing the samples in $5 \mathrm{M}$ nitric acid under ultrasonication at room temperature for 5 minutes. The weight loss of the etched samples was less than $5 \%$. Samples with porosities higher than $70 \%$ were not etched, because etching could easily result in a weight loss higher than $10 \%$ and therefore significant changes in the porous structure.

\subsection{Electrochemical surface area measurement}

The electroactive surface area measurement of the LCS porous $\mathrm{Cu}$ was carried out following a similar procedure reported in. ${ }^{\mathbf{1 2}}$ Fig. 2a shows a typical current-potential plot of the porous $\mathrm{Cu}$ samples in $0.1 \mathrm{M} \mathrm{KOH}$ solution in the potential range of -1.6 to $0.7 \mathrm{~V}$ at a scan rate of $0.01 \mathrm{~V} \mathrm{~s}^{-1}$, which had a similar shape as that of a solid $\mathrm{Cu}$ electrode but with a different magnitude (see ESI Fig. S2 $\dagger$ ). There are two current peaks in the forward sweeping part of the curve. The peaks, 1 and 2 , indicate two different chemical reactions, (1) and (2), respectively: ${ }^{24,25}$

$$
\begin{gathered}
2 \mathrm{Cu}+2 \mathrm{OH}^{-} \rightarrow \mathrm{Cu}_{2} \mathrm{O}+\mathrm{H}_{2} \mathrm{O}+2 \mathrm{e} \\
\mathrm{Cu}+2 \mathrm{OH}^{-} \rightarrow \mathrm{Cu}(\mathrm{OH})_{2}+2 \mathrm{e}
\end{gathered}
$$

Reactions (1) and (2) were controlled by the diffusion of $\mathrm{Cu}^{+}$ in the solid electrode and the diffusion of $\mathrm{OH}^{-}$in the electrolyte, respectively. ${ }^{\mathbf{2 4 2 5}}$ Both reactions were used to measure the electroactive surface areas with an aim to study the effects of the chosen reaction and the diffusion layer thickness.

Seven copper plates with known geometric surface areas were used to determine the relations between peak current and surface area for copper (see ESI Fig. S3†). The copper plates were ground by sandpapers (grits 80, 320, 600 and 1200), polished by cloths ( 6 and $1 \mu \mathrm{m})$ and further polished by a silk-type cloth pad

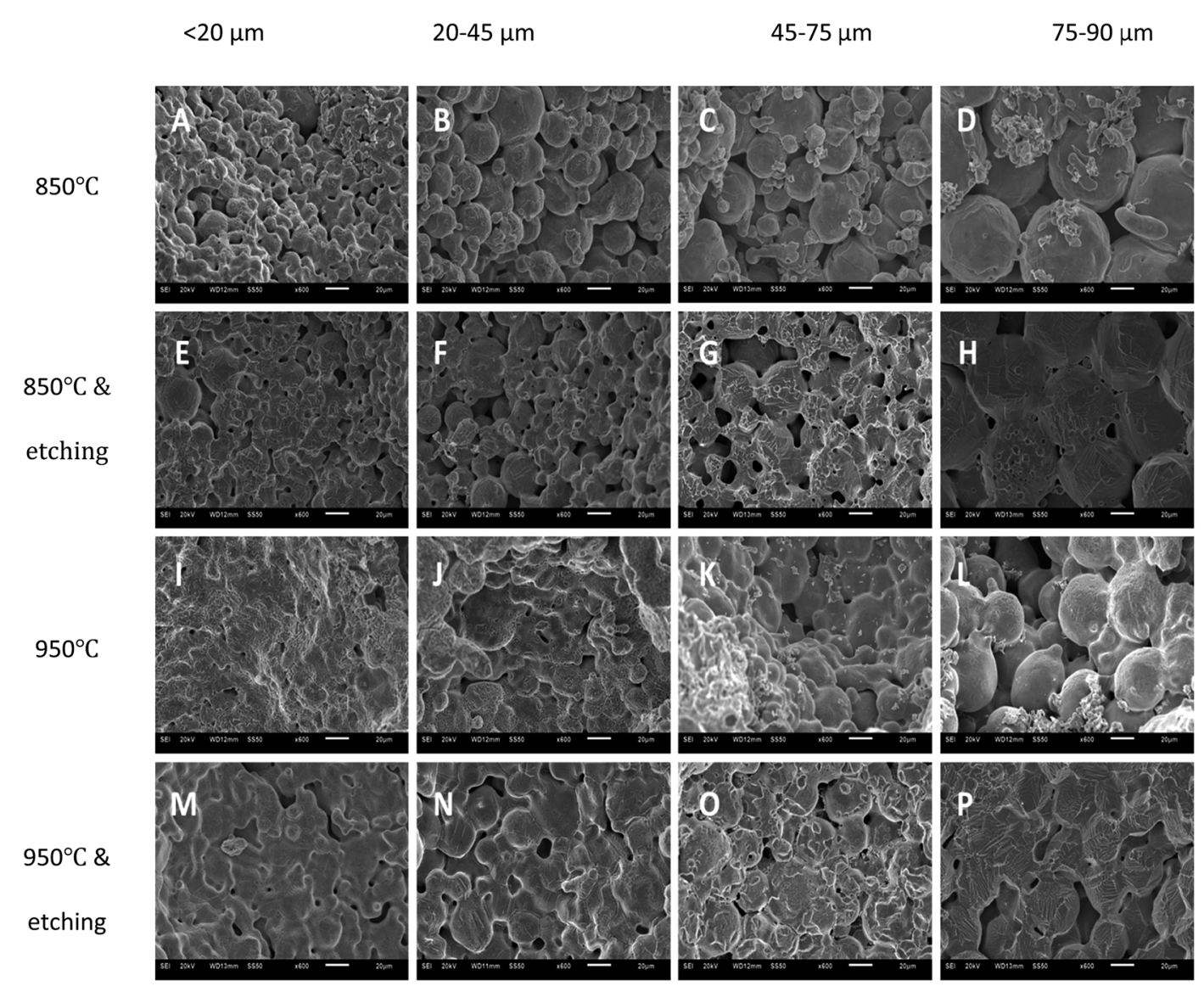

Fig. 3 SEM images of the LCS porous Cu samples with different Cu particle sizes and processing conditions. 
with a $0.04 \mu \mathrm{m}$ colloidal silica suspension to achieve a mirror finish. The electroactive surface areas of the copper plates can be regarded as equal to their geometric surface areas. Fig. 2b shows that there are linear relations between peak current and surface area for both peaks 1 and 2, and the relations can be expressed quantitatively by:

$$
\begin{aligned}
& A_{1}=17026.2 I_{\mathrm{p} 1} \\
& A_{2}=3525.8 I_{\mathrm{p} 2}
\end{aligned}
$$

where $A\left(\mathrm{~cm}^{2}\right)$ is the electroactive surface area and $I_{\mathrm{p}}(A)$ is the peak current. The subscripts 1 and 2 designate peak 1 and peak 2, respectively. For a solid $\mathrm{Cu}$ plate, the electroactive surface area equals to the geometric surface area and is independent of the current peak used. For a porous $\mathrm{Cu}$ sample, the electroactive surface area depends on the electrochemical reaction in consideration and has different values for different peaks. Nevertheless, the relations (3) and (4) can be used to determine the electroactive surface areas of the porous copper samples corresponding to reactions (1) and (2), respectively. The volumetric electroactive surface areas measured by peak $1, A_{\mathrm{Cu}^{+}}$, and peak $2, A_{\mathrm{OH}^{-}}$, can be calculated by dividing $A_{1}$ and $A_{2}$ by the volume of the porous $\mathrm{Cu}$ sample, respectively. It is worth mentioning that the proportionality coefficient in eqn (4) has a different value from ${ }^{12}$ because different scan rates and unit of current were used. Considering that the peak current is proportional to the square root of scan rate, the difference in the values between eqn (4) and ref. 10 is less than $15 \%$, mainly due to experimental variability.

The effect of electrolyte resistance, which was not mentioned in ref. 9, was considered in this work. The high surface area of the porous copper resulted in currents in the order of $10 \mathrm{~mA}$ when $0.1 \mathrm{M} \mathrm{KOH}$ was used. The high currents can cause significant distortions in the voltammetry if the solution resistance is not compensated. ${ }^{17}$ To this end, the "IR-compensation" feature in the potentiostat was used to automatically compensate the potential signal for solution resistance for porous samples. The compensation of solution resistance was not necessary for copper plates, because of the low current density generated.

The real surface area of the porous $\mathrm{Cu}$ samples was measured by the double layer capacitance method, following the procedure reported in. ${ }^{2}$ The double layer capacitance of the LCS porous copper was determined from the charge/ discharge current (eqn (5)). ${ }^{26}$ Because the specific capacitance for the interface of copper in $0.1 \mathrm{M} \mathrm{KOH}$ solution is $0.02 \mathrm{mF} \mathrm{cm}{ }^{2},{ }^{27}$ the real surface area of the porous copper can be determined by eqn (6):
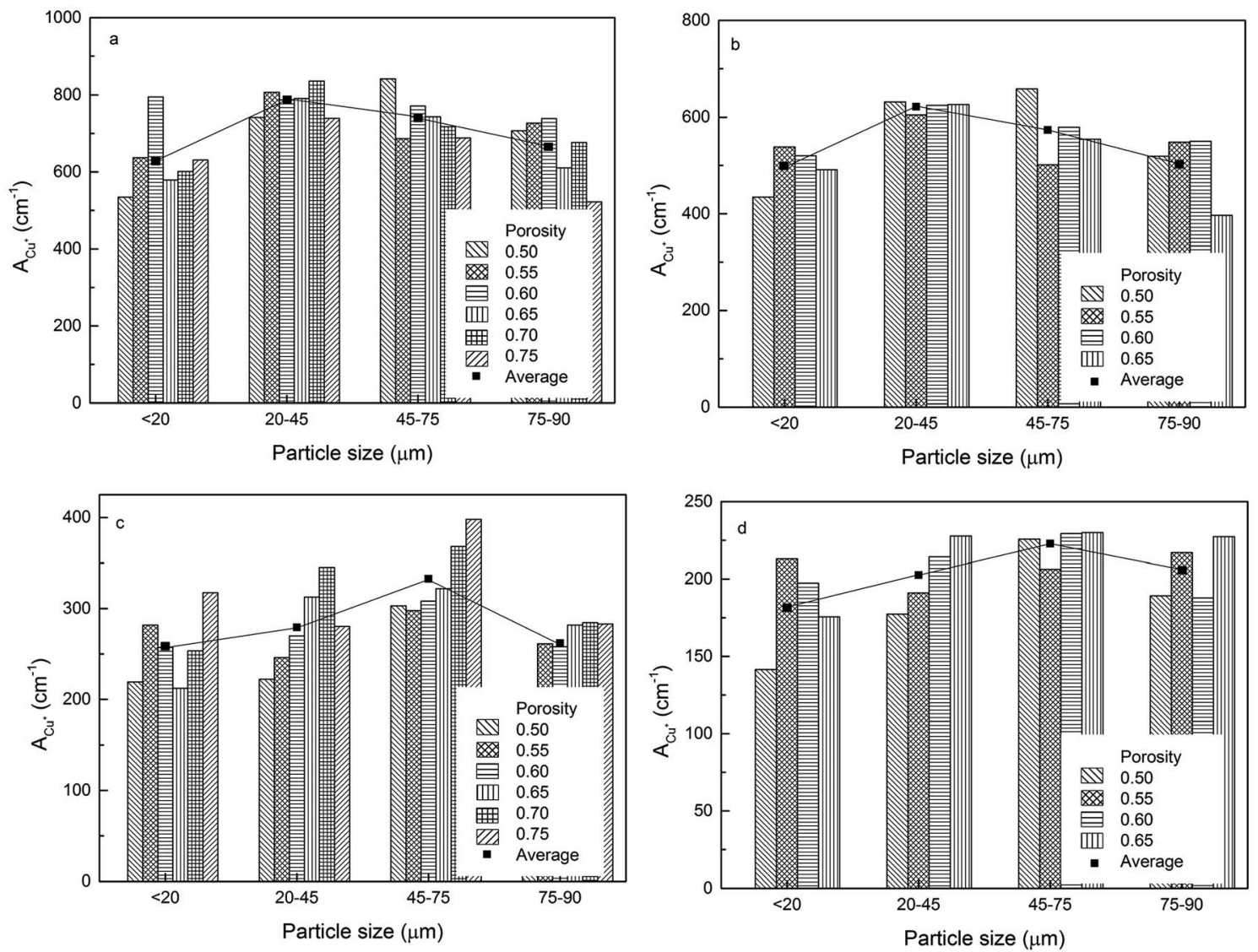

Fig. 4 Volumetric electroactive surface area, measured by the diffusion of $\mathrm{Cu}^{+}$, of the LCS porous Cu samples with different particle sizes for different porosities, manufactured by (a) $850{ }^{\circ} \mathrm{C}$ sintering, (b) $850{ }^{\circ} \mathrm{C}$ sintering and etching, (c) $950{ }^{\circ} \mathrm{C}$ sintering and (d) $950{ }^{\circ} \mathrm{C}$ sintering and etching. 


$$
\begin{gathered}
C=\frac{I}{v} \\
A_{\mathrm{r}}=\frac{C}{0.02}
\end{gathered}
$$

where $C(\mathrm{mF})$ is the double layer capacitance, $I(\mathrm{~mA})$ is the charge/discharge current, $v\left(\mathrm{~V} \mathrm{~s}^{-1}\right)$ is the applied scan rate and $A_{\mathrm{r}}\left(\mathrm{cm}^{2}\right)$ is the real surface area. It should be noted that the value of $I$ is half the difference between the charge and discharge current rather than the difference as erroneously reported in. ${ }^{\mathbf{1 2}}$ The current-potential plots of the LCS $\mathrm{Cu}$ for real surface area measurement can be seen in ESI Fig. S4. $\dagger$

\section{Results and discussions}

\subsection{Morphology of the LCS porous copper}

Fig. 3 shows the SEM images of the LCS porous $\mathrm{Cu}$ samples manufactured with different $\mathrm{Cu}$ particle sizes and different sintering and chemical treatment conditions. The samples sintered at $850{ }^{\circ} \mathrm{C}$ (first row) have rough surfaces, with the initial spherical $\mathrm{Cu}$ particles easily discernible. It can also be observed that the smaller the $\mathrm{Cu}$ particles, the thicker the sintering necks relative to the particle size. The samples sintered at $850{ }^{\circ} \mathrm{C}$ and etched (second row) show smoother surfaces, revealing strong sintering necks and making original particles less visible, especially in the small $\mathrm{Cu}$ particle sample (Fig. 3E). The samples sintered at $950{ }^{\circ} \mathrm{C}$ (third row) are apparently denser and have thicker sintering necks than the samples sintered at $850{ }^{\circ} \mathrm{C}$ (first row) for any given $\mathrm{Cu}$ particle size. The sample made from the smallest particles (Fig. 3I) is fully sintered with the original particles barely discernible. The original particles can still be seen in the samples made form larger particles (Fig. 3J-L), but they are less noticeable than in the samples sintered at $850{ }^{\circ} \mathrm{C}$ (first row). The samples sintered at $950{ }^{\circ} \mathrm{C}$ and subsequently etched (fourth row) show more flat surfaces, with the original particles hardly noticeable for all samples.

\subsection{Effect of particle size on surface areas}

The volumetric electroactive surface areas, measured by the diffusion of $\mathrm{Cu}^{+}\left(A_{\mathrm{Cu}^{+}}\right)$and $\mathrm{OH}^{-}\left(A_{\mathrm{OH}^{-}}\right)$, and the volumetric real surface area $\left(A_{\mathrm{r}}\right)$ of the LCS porous $\mathrm{Cu}$ samples with different particle sizes and porosities, manufactured under different process conditions, are shown in Fig. 4-6, respectively. All data are also available in ESI Tables S1-S3.† It is obvious that the surface areas are affected by both $\mathrm{Cu}$ particle size and porosity for all manufacturing and treatment conditions. For each process condition, the surface areas vary with porosity without
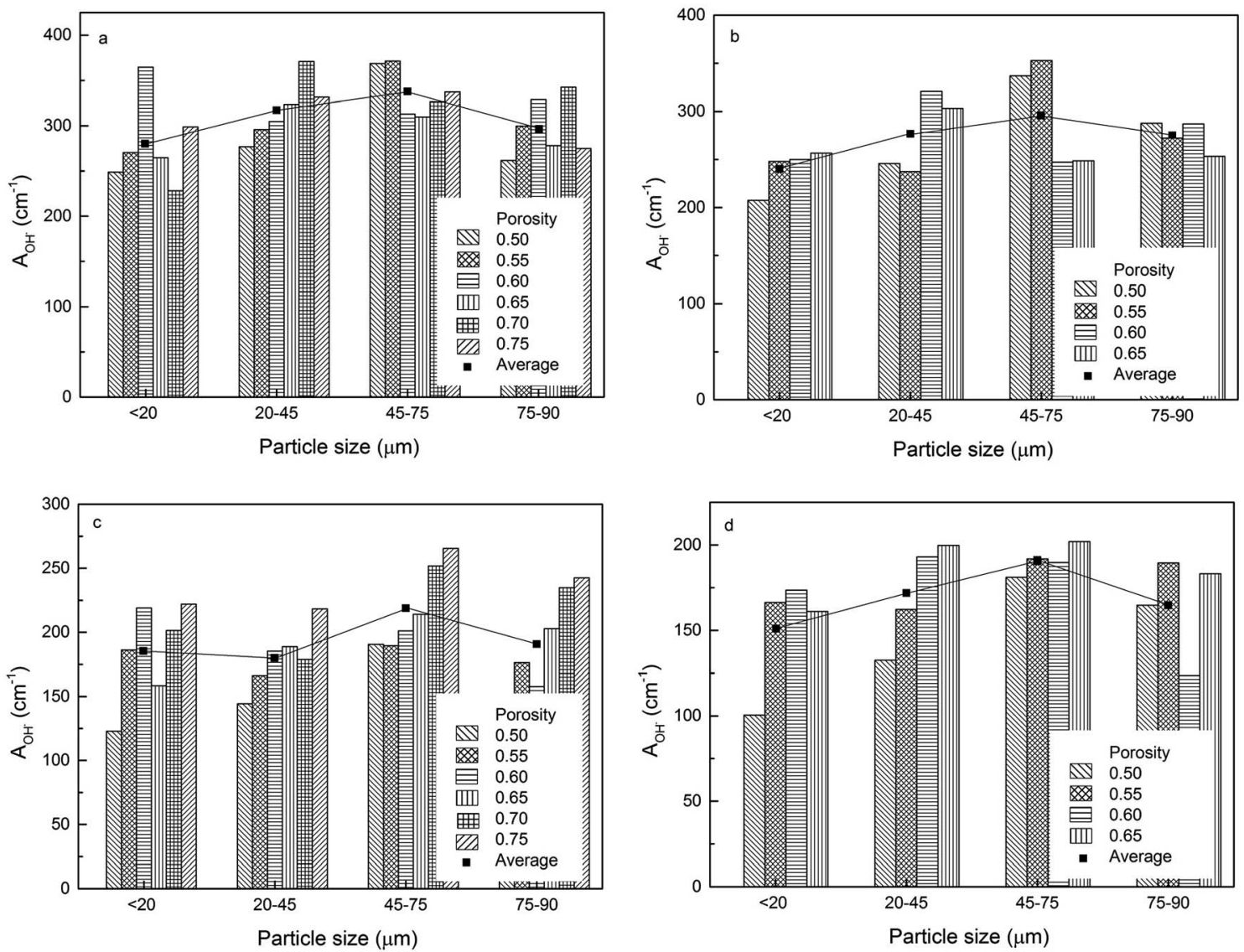

Fig. 5 Volumetric electroactive surface area, measured by the diffusion of $\mathrm{OH}^{-}$, of the LCS porous Cu samples with different particle sizes for different porosities, manufactured by (a) $850^{\circ} \mathrm{C}$ sintering, (b) $850{ }^{\circ} \mathrm{C}$ sintering and etching, (c) $950{ }^{\circ} \mathrm{C}$ sintering and (d) $950{ }^{\circ} \mathrm{C}$ sintering and etching. 

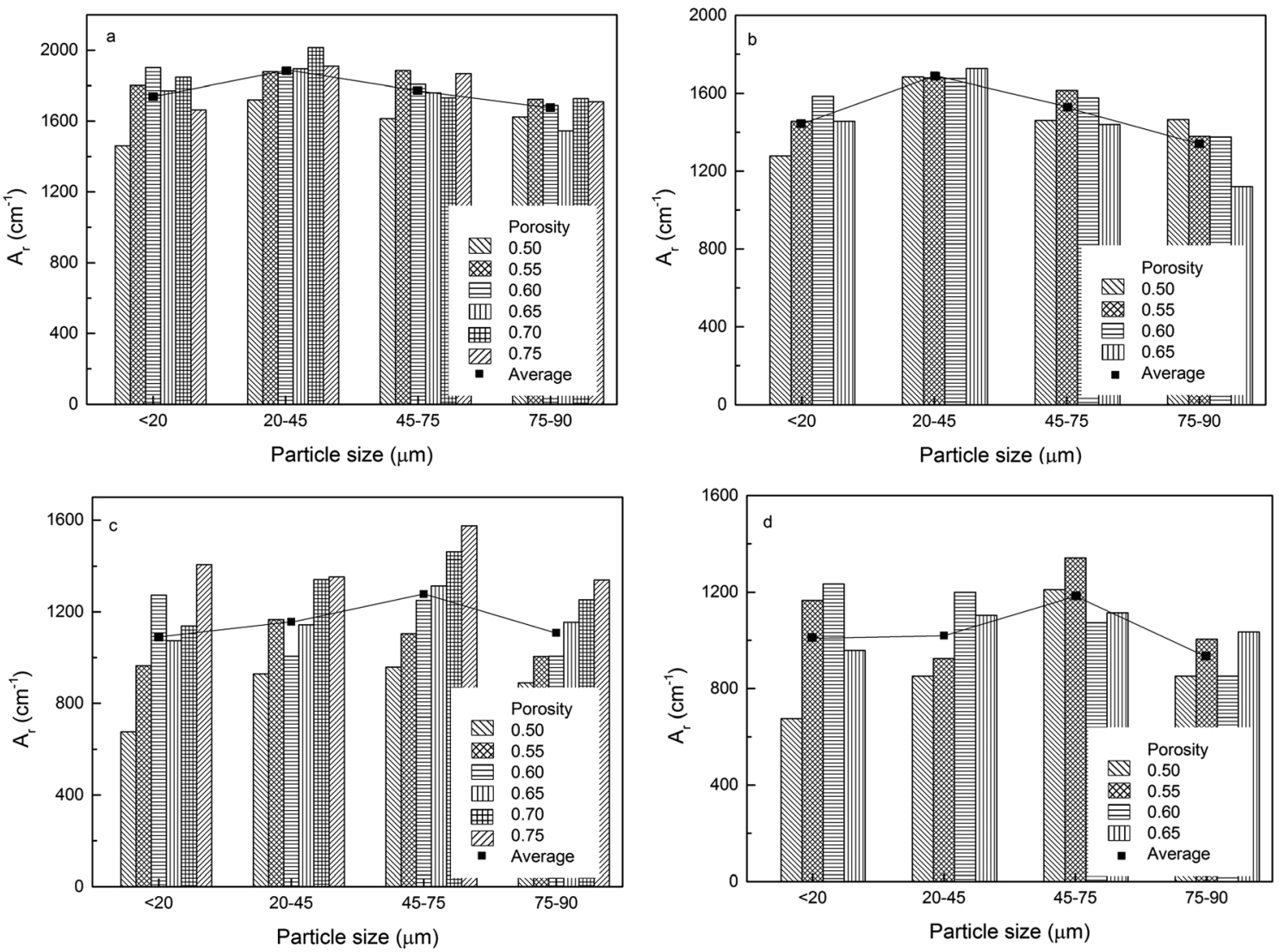

Fig. 6 Volumetric real surface area of the LCS porous Cu samples with different particle sizes for different porosities, manufactured by (a) $850{ }^{\circ} \mathrm{C}$ sintering, (b) $850^{\circ} \mathrm{C}$ sintering and etching, (c) $950^{\circ} \mathrm{C}$ sintering and (d) $950{ }^{\circ} \mathrm{C}$ sintering and etching.

any particular pattern, in agreement with. ${ }^{12}$ In order to remove the effect of porosity and focus on the effect of particles size, the average volumetric electroactive surface area for each particle size is also shown in the graphs. Fig. 4-6 show that $\mathrm{Cu}$ particle size has a moderate effect on the electroactive and real surface areas. As a general trend, both the electroactive surface areas (Fig. 4 and 5) and the real surface area (Fig. 6) first increase and then decrease with particle size. The maximum surface area values are achieved in the samples either with a particle size of 20-45 $\mu \mathrm{m}$ or with a particle size of $45-75 \mu \mathrm{m}$.

The effect of $\mathrm{Cu}$ particle size on surface area is twofold. On the one hand, smaller particles offer a higher total surface area. ${ }^{12}$ On the other hand, it is easier to sinter smaller particles to achieve a denser structure, resulting in a huge loss in surface area. In contrast, larger $\mathrm{Cu}$ particles have lower total surface area but experience less loss in surface area during sintering. Overall, the effect of particle size on the surface area depends on which of the two mechanisms is more significant. As a consequence, samples with a medium particle size range often have the highest surface areas.

\subsection{Effect of sintering temperature and chemical etching on surface areas}

Fig. 7 shows the effects of sintering temperature and etching treatment on the electroactive and real surface areas. Sintering temperature has a great effect on the surface areas. Compared with the samples sintered at $850{ }^{\circ} \mathrm{C}$, the samples sintered at $950{ }^{\circ} \mathrm{C}$, both before and after etching, have reductions of approximately $61 \%$, on average, in the electroactive surface area measured by the diffusion of $\mathrm{Cu}^{+}$(Fig. 7a) and $37 \%$ in the electroactive surface area measured by the diffusion of $\mathrm{OH}^{-}$ (Fig. 7b), and $31 \%$ in the real surface area (Fig. $7 \mathrm{c}$ ). The reductions are due to smoother surfaces and thickened sintering necks (Fig. 3), as a result of the increased densification at a higher sintering temperature.

Etching treatment also has a significant effect on the surface areas. There is a strong correlation between the surface areas before and after etching. The chemical etching resulted in reductions of $25 \%$ in the electroactive surface area measured by the diffusion of $\mathrm{Cu}^{+}$(Fig. 7a) and 9\% in the electroactive surface area measured by the diffusion of $\mathrm{OH}^{-}$(Fig. $7 \mathrm{~b}$ ), and $11 \%$ in the real surface area (Fig. 7c). That is because chemical etching significantly reduced the surface roughness of the LCS Cu samples, as evidenced in Fig. 3.

\subsection{Effect of chemical reaction on electroactive surface area}

Fig. 8 shows the relations between the volumetric electroactive surface area and real surface area for the LCS porous $\mathrm{Cu}$ samples manufactured with different $\mathrm{Cu}$ particles sizes and sintered at $850{ }^{\circ} \mathrm{C}$ and $950{ }^{\circ} \mathrm{C}$, before and after chemical 

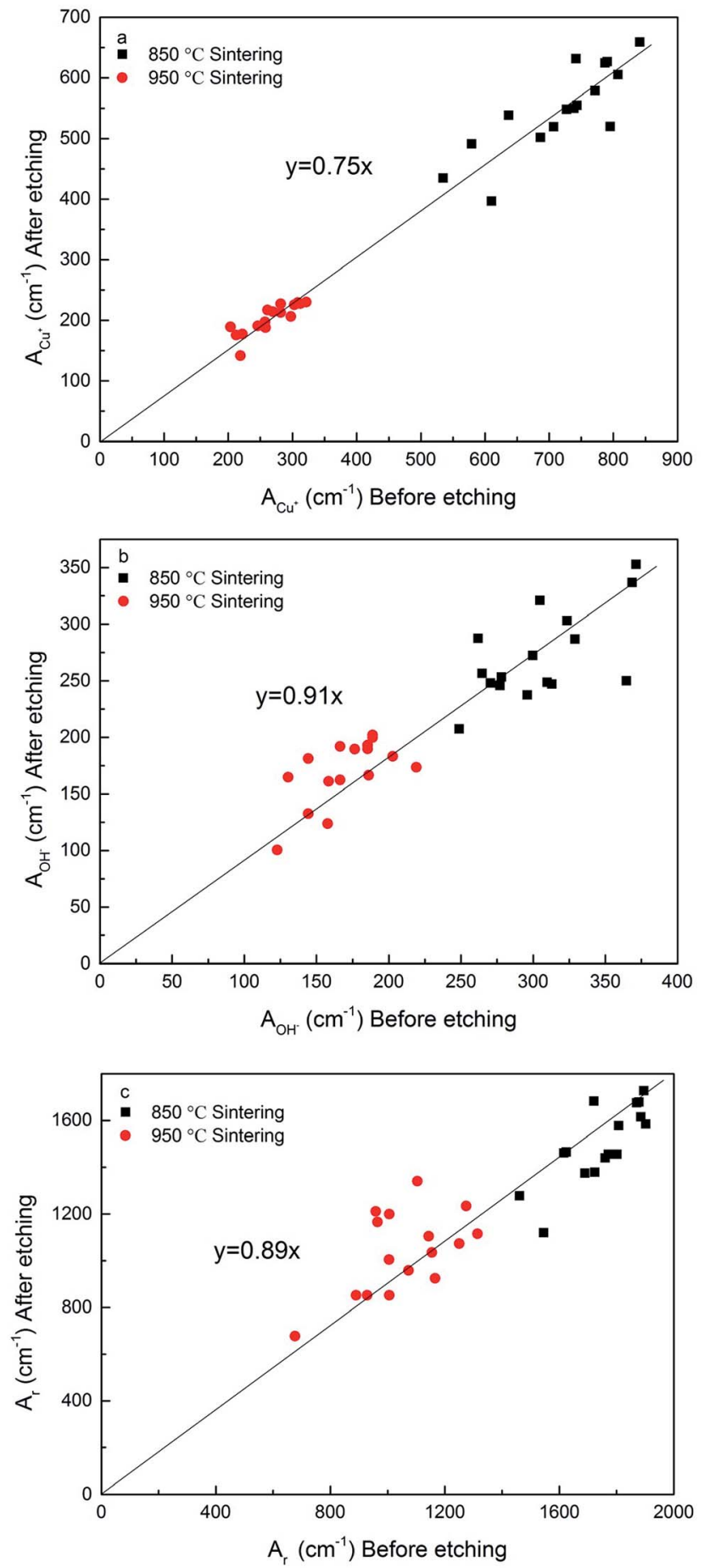

Fig. 7 Correlations between surface areas of samples with and without the etching treatment for the LCS porous Cu samples sintered at two different temperatures: (a) $A_{\mathrm{Cu}^{+}}$(b) $A_{\mathrm{OH}^{-}}$and (c) $A_{\mathrm{r}}$.

etching. A moderate level correlation exists between the electroactive and real surface areas. The electroactive surface area measured by the diffusion of $\mathrm{OH}^{-}$is approximately $16-18 \%$ of the real surface area, regardless of the manufacturing and treatment conditions. The ratio between the electroactive surface area measured by the diffusion of $\mathrm{Cu}^{+}$and the real surface area depends on the manufacturing conditions. The ratio was approximately $40 \%$ for samples sintered at $850^{\circ} \mathrm{C}$, and reduced to $37 \%$ after etching. The ratio was $24 \%$ for samples sintered at $950{ }^{\circ} \mathrm{C}$ and further reduced to $19 \%$ after etching.

It was evident that the electroactive surface area depends on the electrochemical reaction being considered and the diffusion species involved in the reaction. The differences between $A_{\mathrm{OH}^{-}}$, $A_{\mathrm{Cu}^{+}}$and $A_{\mathrm{r}}$ can be explained by considering the thickness of the diffusion layer involved in the reaction. The Nernst diffusion layer thickness, $\delta$, can be calculated by ${ }^{28}$

$$
\delta=\sqrt{\frac{D R T}{n F v}}
$$

where $D$ is the diffusion coefficient $\left(2 \times 10^{-5} \mathrm{~cm} \mathrm{~s}^{-1}\right.$ for $\mathrm{OH}^{-}$in the electrolyte and $1 \times 10^{-8} \mathrm{~cm} \mathrm{~s}^{-1}$ for $\mathrm{Cu}^{+}$in solid $\mathrm{Cu},{ }^{24} R$ is the gas constant (8.134 $\mathrm{J} \mathrm{K}^{-1} \mathrm{~mol}^{-1}$ ), $T$ is the temperature (298 $\left.\mathrm{K}\right), n$ is the number of electrons transferred in the reaction ( 2 for both reactions (1) and (2)), $F$ is the Faradays constant (96 $485 \mathrm{C}$ $\left.\mathrm{mol}^{-1}\right)$ and $v$ is the applied scan rate $\left(0.01 \mathrm{~V} \mathrm{~s}^{-1}\right)$. The diffusion layer thicknesses for $\mathrm{OH}^{-}$and $\mathrm{Cu}^{+}$, calculated by eqn (7), are about $50 \mu \mathrm{m}$ and $1 \mu \mathrm{m}$, respectively.

The real surface area is the maximum electroactive surface area that can contribute to any electrochemical reactions. Because no diffusion of reactive species is involved in the measurements of real surface area, the Nernst diffusion layer thickness can be regarded as zero. The surface features at all length scales contribute to the surface area. For reaction (1) controlled by the diffusion of $\mathrm{Cu}^{+}$, however, any features less than $1 \mu \mathrm{m}$ in the LCS porous $\mathrm{Cu}$, e.g., the very fine interstices/ protrusions in the metal matrix formed by the sintered $\mathrm{Cu}$ particles, will be depleted with $\mathrm{Cu}^{+}$ions rapidly due to limited supply characteristic of thin layer diffusion, as shown schematically in Fig. 9. The species are depleted because of a longer distance of diffusion from the electrolyte reservoir to the electrode surface at which the reaction takes place. Those interstices or protrusions with a size smaller than $1 \mu \mathrm{m}$ can be ignored by the reaction, ${ }^{14-16}$ as they do not contribute fully to the current density and thus cannot be detected. The electroactive surface area is effectively the contour or boundary of the diffusion layer within the solid $\mathrm{Cu}$. Similarly, for reaction (2) controlled by the diffusion of $\mathrm{OH}^{-}$, any features less than $50 \mu \mathrm{m}$ in the LCS porous $\mathrm{Cu}$ will not contribute fully to the current density and thus cannot be detected as part of the electroactive surface area. In this case, the electroactive surface area is effectively the contour or boundary of the diffusion layer within the electrolyte (Fig. 9).

In short, the double capacitance method and the cyclic voltammetry method based on diffusion controlled reactions can measure the electroactive surface areas at different length scales. The double capacitance method can detect all features of the surface. The $\mathrm{CV}$ method based on the diffusion of $\mathrm{Cu}^{+}$ions can only detect surface features bigger than $1 \mu \mathrm{m}$, while the CV method based on the diffusion of $\mathrm{OH}^{-}$ions can only detect surface features bigger than $50 \mu \mathrm{m}$. As a consequence, the real surface area is greater than the electroactive surface area for $\mathrm{Cu}^{+}$ diffusion, which in turn is greater than the electroactive surface area for $\mathrm{OH}^{-}$diffusion. 

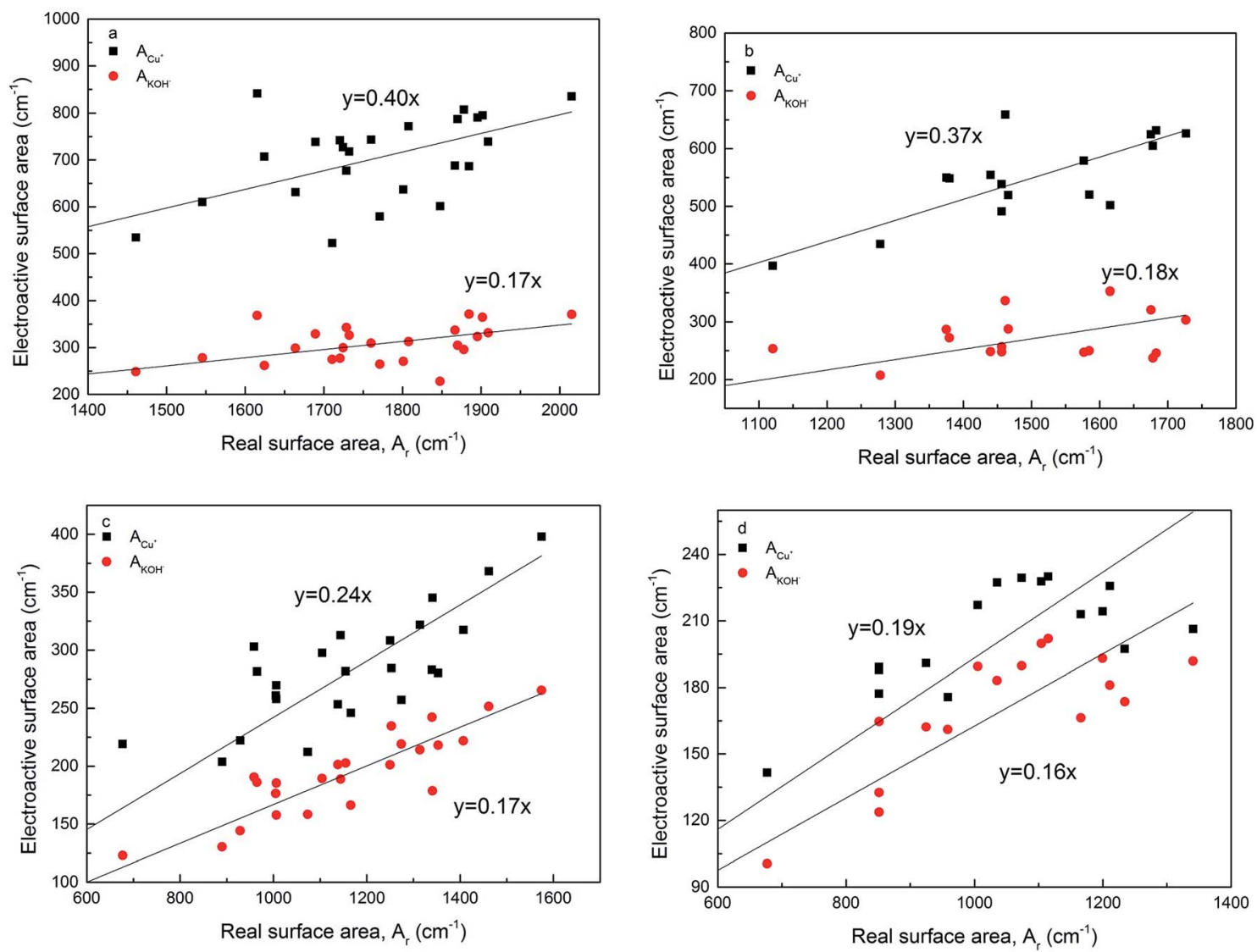

Fig. 8 Correlations between electroactive surface area and real surface area for the LCS porous Cu samples sintered at (a) $850{ }^{\circ} \mathrm{C}$, (b) $850{ }^{\circ} \mathrm{C}$ and etching, (c) $950^{\circ} \mathrm{C}$, and (d) $950^{\circ} \mathrm{C}$ and etching.

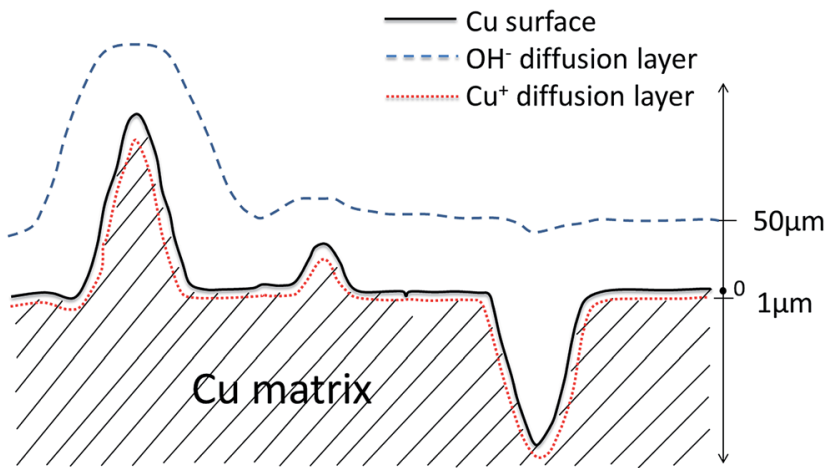

Fig. 9 Schematic of diffusion layers of $\mathrm{OH}^{-}$and $\mathrm{Cu}^{+}$at the interface between Cu matrix and electrolyte.

Fig. 8 also shows that while the ratio between $A_{\mathrm{OH}^{-}}$and $A_{\mathrm{r}}$ did not change with process conditions, the ratio between $A_{\mathrm{Cu}^{+}}$and $A_{\mathrm{r}}$ changes with sintering temperature and chemical etching. The different behaviour in $A_{\mathrm{Cu}^{+}}$is likely because reaction (1) is not solely controlled by $\mathrm{Cu}^{+}$diffusion. In the region of the solid electrode near the interface with the electrolyte, there is sufficient supply of $\mathrm{OH}^{-}$ions and the reaction is controlled by the $\mathrm{Cu}^{+}$diffusion in the solid phase. In the region farther away from the interface with the electrolyte, i.e., in the interior of the cell wall, the supply of $\mathrm{OH}^{-}$ions is also limited by the diffusion of the $\mathrm{OH}^{-}$ions in the electrolyte. The reaction becomes both $\mathrm{Cu}^{+}$ and $\mathrm{OH}^{-}$diffusion controlled.

\section{Conclusions}

(1) Two electrochemical reactions are involved in the cyclic voltammetry of $\mathrm{Cu}$. The electroactive surface area of the LCS porous $\mathrm{Cu}$ depends on the reaction being considered and the diffusion layer thickness associated with the reaction.

(2) A thicker diffusion layer results in a lower electroactive surface area. The electroactive surface areas based on the diffusion of $\mathrm{Cu}^{+}$in the solid phase and $\mathrm{OH}^{-}$in the electrolyte, with the diffusion layer thicknesses of $1 \mu \mathrm{m}$ and $50 \mu \mathrm{m}$, are approximately $16-18 \%$ and $19-40 \%$ of the real surface area, respectively. The former is largely independent of the manufacturing conditions, while the latter depends on the sintering temperature and etching treatment.

(3) The particle size of the $\mathrm{Cu}$ powder used to manufacture the LCS porous $\mathrm{Cu}$ had a modest effect on the electroactive and real surface areas, with the medium particle sizes, $20-45 \mu \mathrm{m}$ or 45-75 $\mu \mathrm{m}$, showing the highest surface areas.

(4) Increasing sintering temperature from $850{ }^{\circ} \mathrm{C}$ to $950{ }^{\circ} \mathrm{C}$ reduced the electroactive and real surface areas by $31-61 \%$. Chemical etching reduced the electroactive and real surface areas by $9-25 \%$. 


\section{References}

1 M. F. Ashby, T. Evans, N. A. Fleck, J. Hutchinson, H. Wadley and L. Gibson, Metal Foams: A Design Guide: A Design Guide, Elsevier, 2000.

2 X. Huang, J. Tu, X. Xia, X. Wang and J. Xiang, Electrochem. Commun., 2008, 10, 1288-1290.

3 H. Wang, Q. Pan, X. Wang, G. Yin and J. Zhao, J. Appl. Electrochem., 2009, 39, 1597-1602.

4 R. Shivkumar, G. P. Kalaignan and T. Vasudevan, J. Power Sources, 1998, 75, 90-100.

5 K. Naito, T. Matsunami, K. Okuno, M. Matsuoka and C. Iwakura, J. Appl. Electrochem., 1993, 23, 1051-1055.

6 M. C. Tucker, G. Y. Lau, C. P. Jacobson, L. C. DeJonghe and S. J. Visco, J. Power Sources, 2007, 171, 477-482.

7 S. Molin, B. Kusz, M. Gazda and P. Jasinski, J. Power Sources, 2008, 181, 31-37.

8 V. Ganesh, V. Lakshminarayanan and S. Pitchumani, Electrochem. Solid-State Lett., 2005, 8, A308-A312.

9 F. Bidault, D. Brett, P. Middleton, N. Abson and N. Brandon, Int. J. Hydrogen Energy, 2009, 34, 6799-6808.

10 A. Đukić, V. Alar, M. Firak and S. Jakovljević, J. Alloys Compd., 2013, 573, 128-132.

11 G. W. Nyce, J. R. Hayes, A. V. Hamza and J. H. Satcher, Chem. Mater., 2007, 19, 344-346.

12 K. K. Diao, Z. Xiao and Y. Y. Zhao, Mater. Chem. Phys., 2015, 162, 571-579.

13 P. Delahay, New Instrumental Methods, in Electrochemistry: Theory, Instrumentation, and Applications to Analytical and Physical Chemistry. With a Chapter on High-frequency Methods, Interscience Publishers, 1954.
14 E. O. Barnes, X. Chen, P. Li and R. G. Compton, J. Electroanal. Chem., 2014, 720, 92-100.

15 T. J. Davies and R. G. Compton, J. Electroanal. Chem., 2005, 585, 63-82.

16 T. J. Davies, S. Ward-Jones, C. E. Banks, J. del Campo, R. Mas, F. X. Munoz and R. G. Compton, J. Electroanal. Chem., 2005, 585, 51-62.

17 R. E. Smith, T. J. Davies, N. D. B. Baynes and R. J. Nichols, J. Electroanal. Chem., 2015, 747, 29-38.

18 M. Grdeń, M. Alsabet and G. Jerkiewicz, ACS Appl. Mater. Interfaces, 2012, 4, 3012-3021.

19 Y. H. Tan, J. A. Davis, K. Fujikawa, N. V. Ganesh, A. V. Demchenko and K. J. Stine, J. Mater. Chem., 2012, 22, 6733-6745.

20 S. Rausch and H. Wendt, J. Electrochem. Soc., 1996, 143, 2852-2862.

21 R. Campbell, M. G. Bakker, C. Treiner and J. Chevalet, J. Porous Mater., 2004, 11, 63-69.

22 Y. Y. Zhao, T. Fung, L. P. Zhang and F. L. Zhang, Scr. Mater., 2005, 52, 295-298.

23 Y. Y. Zhao and L. P. Zhang, Proc. Inst. Mech. Eng., Part B, 2008, 222, 267-271.

24 N. Hampson, J. Lee and K. Macdonald, J. Electroanal. Chem. Interfacial Electrochem., 1972, 34, 91-99.

25 J. Ambrose, R. Barradas and D. Shoesmith, J. Electroanal. Chem. Interfacial Electrochem., 1973, 47, 47-64.

26 A. Lewandowski, P. Jakobczyk and M. Galinski, Electrochim. Acta, 2012, 86, 225-231.

27 A. Łukomska and J. Sobkowski, J. Electroanal. Chem., 2004, 567, 95-102.

28 C. Amatore, Physical Electrochemistry: Principles, Methods and Applications, 1995, 4, 131-208. 